\title{
IDENTITY CONSTRUCTION ON SOCIAL NETWORKS THROUGH THE PRISM OF DEFENSE MECHANISM “OVERCOMPENSATION”
}

\author{
Tetiana Khraban \\ Ph.D., Head of the Department of Foreign Languages, \\ Military Institute of Telecommunications and Information Technologies, Ukraine \\ e-mail: xraban.tatyana@gmail.com,orcid.org/0000-0001-5169-5170
}

\section{Summary}

The aim of the article is to study the identity construction in Ukrainian sector of Facebook social network through the prism of defense mechanism "overcompensation". Psycholinguistic research methods, namely discourse analysis, the method of contextual and intuitive logical interpretation analysis are used in this empirical, inductive study. The study identified that the most desirable characteristics for an individual are hardline attitude, self-confidence, self-control, persistence, buoyancy, ambition for self-development and self-actualization, steadfastness, rebelliousness, adventurism, humanity, kindness. The Ukrainian social network users are strongly attracted by such gender roles as "real man" and "strong woman" as well as such situational social roles as "powerful man", "rebel”, "learner", “cynic", "expert-adviser", "nihilist", "sage", "leader", "hedonist". We argue that an individual who constructs his/her personal identity through the defense mechanism "overcompensation" has clearly demonstrated need for power, an individual is convinced of the moral righteousness of what he/she believes in. The need for power motivates an individual in quest for leadership. In this case, an individual is focused on charismatic leadership, that is, he/she positions himself/herself as a person who, by virtue of his/her personal abilities and qualities, is able to have a profound and extraordinary influence on the people around him/her. The preferable psychological types of leader are "hero leader", "leader-standard", "erudite leader". The charismatic leadership is only an immanent orientation of consciousness toward a desired identity, no matter it is real or imagined, but this orientation certainly affects the real identity construction.

Keywords: leadership, social networks, identity construction, discourse analysis.

DOI https://doi.org/10.23856/4308

\section{Introduction}

1.1. Interdisciplinary approach to the study of identity. The potential of mass communication technologies, social networks and the blogosphere for communicating with a wider audience inspires research studies, which focus on scientific understanding of modern communication processes from the perspective of the impact of innovative technology on the transformation of various social practices. Research interest in the relevant processes in the areas concerning Internet communication has been reflected in various fields of scientific knowledge, namely philology, psychology, sociology, cultural studies, philosophy, etc. The feasibility of integrating interdisciplinary viewpoints, research approaches and methods developed within the framework of long-established scientific disciplines has contributed to the emergence of a number of interdisciplinary studies (visual studies, digital studies, media studies, etc.). Experience of interdisciplinary research in the field of modern media and communications has proved the usefulness of the interdisciplinary approach to the study of identity (both personal and 
social) in the global communication environment in general, and in social networks in particular. Research carried out by Back, Stopfer, Vazire, Gaddis, Schmukle, Egloff, Gosling (Back et al., 2010) substantiated and confirmed by experimental data that social networks have effective potential for studying real identity, since they transmit reliable information about a person (close environment, appearance, interests, likes and dislikes, behaviors, etc.), although certain aspects can be idealized. Despite the fact that modern Internet technologies provide ample opportunities for creating identities, researchers have endeavored to expand the scope of studying the social and communicative features of network user identity beyond the outlined circle of the Internet. The reasons were to be found in the fact that the concept "network culture" is used not only to characterize the communicative environment of the Internet, but also to designate a culture based on network logic. Thus, the concept "network culture" can be applied to all society, whose everyday culture is increasingly represented in the form of network structures (Romm \& Luchikhina, 2011). At present network culture is considered as a new cultural type that has arisen to respond to the spreads of global networks and that is going to replace the culture of postmodernism (Varnelis, 2020). Therefore, identity as an object of research will continue to maintain its current broad scope and relevance in the interdisciplinary discourse of humanitarian knowledge.

1.2. Identity on the Web as an object of research. The research area of identity is complex and multifaceted because social, ethnic (national), personal, gender, professional, religious and other types of identity are investigated at present time. The widest possible definition of the research area of identity has made it possible to bring together the research interests of linguists, psychologists, sociologists, cultural scientists and others. So, analyzing personal identity as a person's awareness of his/her own unity and integrity in space and time, Lysack and Kosenschuk (Lysack \& Kosenchuk, 2016) distinguished in the structure of personal identity two levels, namely individual, which includes a set of unique, peculiar qualities, and sociocultural, which involves identification with the norms of the social environment and with the symbolic world of culture. Based on analysis of impact of a blogosphere and computer games on identification processes in modern society Lysack and Kosenschuk argue that the main mechanisms of identity construction are narration and reflexive interaction. Bogomolova (Bogomolova, 2014) revealed complex differentiation associated with social network users' ambiguous approaches to identity, that are subjective or non-subjective. The first approach to identity takes the form of disclosure of individual's true identity in real and virtual life, the second approach to identity manifests itself in an effort to avoid real contacts, withdraw into virtual space, and in the false identity formation. Borgmann (Borgmann, 2013) argues that the culture of technology, and of information technology particularly, has opened up fields of diversity and contingency that invite us to comprehend our identities in newly responsible, intricate, and open-minded ways. Davis (Davis, 2014) applied classical theories of identity from psychology and sociology to research on the nature of youth identity in a digital age, and conducted an empirical investigation that examined how youth approach identity expression, both online and offline. Terras, Ramsay, Boyle (Terras et al., 2015) outlined a psychologically driven discussion of the similarities and differences between online and offline contexts, and factors that influence online content creation and identity. Researchers point to the need for a comprehensive understanding of two factors, namely the increasing opportunities for content production, interaction and collaboration owing to Web 2.0 technologies and the increasing difficulties for users to reflect upon how these new practices have changed behaviors in online compared with offline environments. In this study the personal identity construction in Ukrainian sector of social network Facebook has been researched from the perspective of the communicative-compensatory 
processes. The scientific value of the research is in the further development of the social identity theory related to the communication adaptation theory. The research purpose is to study the real or projected identity construction in Ukrainian sector of Facebook social network through the prism of the psychological defense mechanism "overcompensation".

\section{Materials \& Methods}

General scientific research methods were used in the study: analysis, classification, observation, description. And furthermore, so it is the empirical, inductive study we believe it would be justifiable to use such psycholinguistic research methods as discourse analysis, the method of contextual and intuitive logical interpretive analysis. The starting point of discourse analysis is the statement that we gain access to reality through a language that not only reflects reality, but also constructs it. In other words, language is not just a channel for information exchange about phenomena, facts or behavior of people, but a mechanism that generates and constitutes the social world (Jorgensen \& Phillips, 2002). When viewed from the perspective of psycholinguistics, the sphere of research interests of identity becomes the external phase of speech production, which affects the grammatical structuring and choice of the word form (the level of the lexical and grammatical structure of the sentence), and the internal phase of the speech-thinking process, in which the explication of intentions is realized, notably the embodiment of the internal (semantic) program of utterance (semantic syntax) and the verbalization of the meanings selected in the internal speech (Akhutina, 2008). At the same time, discourse analysis in the framework of psycholinguistic study on the text organization in specific socio-cognitive practices highlights the reflexive mechanisms settled in these practices and defined by them and, in turn, have a reciprocal effect on the practices (Machikova, 2015). Therefore, in this study the method of contextual and intuitive logical interpretive analysis was used in order to identify the meanings of publications based on personal experience and logical thinking. Content analysis was used to separate certain patterns into thematic groups, which made it possible to identify the dominant senses in publications. The material for this empirical research are text fragments that are posted on the Ukrainian websites of Facebook social network.

\section{Results and discussions}

3.1. Social-psychological approach to identity studies. In this paper the conceptualization of identity is based on the social-psychological approach, according to which identity is not so much an internal integrity as a result of coordination, balance between the potential integrity, personal meanings and societal values, which must be recognized by those whose opinion matters in society (Selyugina, 2012). Thus, under this approach, identity, on the one hand, is a reflection of internal processes, on the other hand, social systems and context are something that can impose an imprint on the individual (Patyrbaeva et al., 2012). The processes of identity constriction at a certain phase of its development and its repeated changes that occur owing to the dialogues between a person and other people are the factors due to which the dichotomies "inner self - consistency with social values", "stability - variability", "integrity - adaptation" become internally integrated (Selyugina, 2012). Mead's theory of the 'Generalized Other' (Mead, 2015) has been chosen as a starting point for this research study. Mead regards a man as a product of biosocial evolution, who has capacity to internalize norms and values, that is, to use the reactions of "Others" to one or another situation to construct his own internal motives for activity. The most important mechanism of social 
norm internalization becomes "role-taking" in which the individual responds to social gestures, and adopts common attitudes. The individual assumes the role of another person, and in each imaginary situation he/she as if plays out a certain scenario in front of an audience (Schwabe, 2019). Each social role promotes certain social values. Since each individual has his/her own understanding of social values, each event becomes relevant in the context of the social roles he or she adopts. In the concept of social personality each actor is regarded in two aspects, namely as a performer and as a stage character, the embodiment of some kind of vital energy, attractive personal and business qualities, the effect of which is reproduced by an individual due to his ability to get into character. By simulating and imitating a certain character, a person tries to ascribe the desirable features to himself/herself and then to anchor his/her image in the minds of other peoples (Goffman, 1958). Developing the general idea of social formation of personality, Lysak and Kosenchuk adopted the concept "roleplaying set". According to their concept, along with a core of personal identity, there is a dynamic roleplaying set that aids a person in adapting to changing life situations, while the core of identity remains intact. Adopting some ideas and opposing others, accepting and sharing new attitudes, values, norms, a person relates them to certain social conditions and environment. That makes it possible to change these attitudes, values, norms depending on the situation, without losing the feeling of own integrity (Lysak \& Kosenchuk, 2016). Based on the foregoing, this study will define a personal identity as the embodiment of all roles, characteristics and capacities that are constructed by an individual in accordance with specific realities of the social fabric. The identity construction can occur in a variety of ways. Thus, according to Goffman (1958), the successful staging of any fictional characters requires the same technique to which human beings resort to cope with adversities; they have to abide by the chosen definition of the situation and engage appropriate means of individual expression (Goffman, 1958).

The characteristic technique employed by the Ukrainian social network users is reckoning themselves among important people, ascribing themselves certain qualities, characteristics, character traits with the help of posting on social network accounts the specially-tailored versions of aphorisms and quotations (real and attributed ones) of famous people with accompanying pictures of these people (famous historical figures, literary and movie characters, mythical heroes, national heroes, etc.). Such posts confirm that in the process of socialization the Ukrainian social network users bring themselves into correlation not only with specific social roles, but also with person-related descriptions that correspond to their own personal tendencies. Such ideal figurative constructions, which have a clearly defined value relevance, bear a symbolic meaning, and are the result of interpretation of culture and its symbols (Assmann, 2013), connect a person with his/her contemporaries, form "a common space of experience, expectation, activity, which binding force provides mutual trust and the possibility to select the guidance appropriate to needs" (Lysak, Kosenchuk, 2016). We consider it is important to note the significance and preference of this technique for constructing identity, which is based on the dialogical mutual affirmation "I - You", "I - We". Thus, in the view of Gladyshev (2012), the ideal form of identity construction is always a dialogic interpenetration, which contributes to the full self-affirmation of both an individual and society and has the highest social value (Gladyshev, 2012). Since identity construction is a phenomenon that takes place at all levels of mental activity, identity should be studied not only as a contents, but also as a process. This approach provides an opportunity not only to explore types of identity, but also to understand the rationale of the choices made. In the view of Tselmina (2003), the starting point for the social-psychological study of identity is identifying specific forms of psychological defense mechanisms. Tselmina argues that the system of psychological defense acts as one of the mental 
determinants of identity, behavior, and personality adaptation, playing along with social and biological determinants an important role in the identity construction (Tselmina, 2003).

In this study social networks are regarded as an environment for compensatory communication, which aims to harmonize the communicative world of the individual if he/her lacks for close emotional ties with people and suffers from deficiency of close, intimate, trusting relationships, that is to say, that is usually experienced in loneliness (Gladyshev, 2001). An important element in studying compensatory communication is a special focus on its pragmatic aspect, that is longing for self-affirmation and gratification of emotional hunger (Vaughan, 1926).

3.2. Components of personal identity in the Ukrainian sector of social networks. Communicative-compensatory processes that find expression in the Ukrainian social network users' posts to be the integration of verbal components with visual images of famous people, are triggered by defense mechanism "overcompensation", which at the linguistic level is manifested in the evaluating some person as a unique individuality worthy of admiration. Thus, the real or illusory image of such person is used by a creator of the image to assert his/her power, significance, value, that is, for self-affirmation and enhancing the status. The study of the Ukrainian sector of social networks found that the personal identity construction through the defense mechanism "overcompensation" is carried out in two directions. In the first case, when identification takes place on the basis of desired characteristics owned by a role model, a person answers the question "What am I like?". The study identified the most important components of personal identity, namely:

1. Communicative component. Interactive ability, that is ability to establish contact and then interact on verbal and empathic levels, is emphasized in the following examples: Never go back to places where you feel ill at ease. Never ask those who once turned down your request. And stay away from those who once hurt you; Never apologize, never explain. Spare your excuses both for ones who like you and, above all, for ones who do not like you. The ones who do not like you will never believe you, and the ones who like will themselves figure out the excuses for you; I explain my success by the fact that I have never made excuses and never listened to excuses (FB). Among the psychological features of communicative personality behavior that are exhibited in the posts and considered the most desirable in the personal identity structure, predominate hardline attitude, categoricalness, inflexibility.

2. Emotional volitional component. In the examples presented, the peculiarities of volitional self-regulations, which are manifested in situation-specific conditions correlated with the certain degree of calamity and challenge are emphasized, namely self-confidence: I want that. So it will be (FB); self-control: The scale of your personality is determined by thresholds of the problem that can drive you crazy; I haven't not fail. I have just found 10,000 ways that won't work (FB); persistence: The hardest thing is to start acting, everything else depends only on perseverance; Sometimes even the maximum of our capabilities is not enough, and we have to do what we previously considered beyond capacity of human beings (FB); buoyancy: I am an optimist. It does not seem too much use being anything else; Success is the ability to move from failure to failure without losing enthusiasm; An optimist is a person who buys a wallet for the last money; A pessimist sees the difficulty in every opportunity; an optimist sees the opportunity in every difficulty (FB).

3. Meaning-making and motivational component related to reflection, self-examination and structuring of perceptual experience. Posts, which reflect the meaning-making and motivational component of personal identity highlight the most important aspects for an individual, which could be objects, subjects or phenomena of environment or inner world of human, and set guidelines for behavior and individual development. Given examples emphasize self-belief: 
Be a light for yourself, be a pillar for yourself, stick to your own truth as the only light; How good it is when the switch of your light is in your own hands (FB); ambition for self-development and self-actualization: To improve means to change, to be perfect means to change often (FB); persistence, perseverance: If the wind will not serve, take to the oars (FB); steadfastness: When we long for life without difficulties, remind us that oaks grow strong in contrary winds and diamonds are made under pressure (FB); decisiveness: You can never cross the ocean unless you have the courage to lose sight of the shore (FB); rebelliousness: Twenty years from now you will be more disappointed by the things that you didn't do than by the ones you did do. So throw off the bowlines. Sail away from the safe harbor. Catch the trade winds in your sails. Explore. Dream. Discover (FB); adventurism: I'd rather die of passion than boredom; History will be kind to me, for I intend to write it (FB).

4. Moral component. Presented examples evince individual's attitude to the moral values, norms, ideals of society, which in the process of interiorization turn into internal motives and personal meanings. The posts emphasize humanity: Remember, if you ever need a helping hand, you'll find one at the end of your arm. As you grow older, you will discover that you have two hands: one for helping yourself, the other for helping others (FB); couth: There is overwhelming evidence that the higher the level of self-esteem, the more likely one will be to treat others with respect, kindness, and generosity (FB); kindness: Weakness is not a lack of strength. Weakness is a lack of kindness (FB).

3.3. Personal identity from the perspective of social roles. In the second case, when identification occurs through social roles, an individual answers the question "Who am I?". The study has revealed social roles the Ukrainian social network users are strongly attracted by, namely:

1. Gender roles. They are represented as the normative varieties of behavior expected from an individual as a person of a particular gender: "real man": An ideal man is an initiator of events, not a consumer of them; The criterion of a real man is not the suffering he has endured. It is the lessons he has learned from suffering; A man of dignity and intelligence can never be ugly; "strong woman": If you regard women as the fair sex, try to drag a blanket at night onto you side (FB).

2. Episodic situation roles, namely "powerful man": Power is a drug. Who tried it at least once is poisoned forever; When eagles are silent, parrots begin to chatter; The Prime Minister of Great Britain has nothing to hide from the President of the United States (FB); "celebrity": My reputation grows with every failure (FB); "maverick", "rebel": There's still time, so run away from the prison you've imprisoned yourself in! A little courage, a little risk is only required. And remember: you have nothing to lose. You can only lose your chains, you can lose your boredom, you can lose that constant feeling inside you that something is missing (FB); "learner": If you don't make a mistake, you cannot learn; In chess you can become a great master only if you realize your own mistakes and weaknesses. Exactly like in life (FB); "cynic": Reading the biography, remember that the truth is never suitable for publication; martyrdom: The only way a man can become famous without ability (FB); "expert-adviser": When you long for something, do your best to achieve it. Even if it doesn't work out, you'll know you have tried your best (FB); "nihilist": Only by denying all views of the public of what you're supposed to be you will learn who you truly are. Only by learning who you are you will foresee who you can become (FB); "sage": Fortune knocks once at every man's door, but a person at this time is often in the nearest pub and does not hear any knock (FB); "leader": If you want to build a ship, you need not gather people, plan, distribute the work, provide an effective tool. It is necessary to fill people with a passion for the nondescript sea. Then they will build a ship themselves (FB); "hedonist": I have taken more out of alcohol than alcohol has taken out of me (FB). 


\section{Conclusions}

In the construction real or projected identity in Ukrainian sector of Facebook social network through the prism of the defense mechanism "overcompensation" the most desirable characteristics and character traits for an individual are hardline attitude, self-confidence, self-control, persistence, buoyancy, ambition for self-development and self-actualization, steadfastness, rebelliousness, adventurism, humanity, kindness. The Ukrainian social network users are strongly attracted by such gender roles as "real man" and "strong woman" as well as such situational social roles as "powerful man", "rebel”, "learner", “cynic”, "expert-adviser”, "nihilist", "sage", "leader", "hedonist". These results prompt the conclusion that an individual who constructs his/her personal identity through the defense mechanism "overcompensation" has clearly demonstrated need for power, he/she is convinced of the moral righteousness of what he/she believes in. The need for power motivates an individual in quest for leadership. In this case, an individual is focused on charismatic leadership, that is, he/she positions himself/herself as a person who, by virtue of his personal abilities and qualities, is able to have a profound and extraordinary influence on the people around him/her. The preferable psychological types of leader are "hero leader" (a person who sacrifices himself for others, has ability to lead people in times of trial, whose courage unites people. People regard hero leader as the standard of justice); "leader-standard" (a person who is loved, idealized and idolized. Leader-standard attracts, charges his/her followers with positive energy); "erudite leader" (a person who is distinguished by the breadth of knowledge). It should be emphasized that the charismatic leadership is only an immanent orientation of consciousness toward a desired identity, no matter it is real or only imagined, but this orientation certainly affects the real identity construction.

\section{References}

Akhutina, T.V. (2008). Porozhdenie rechi: nejrolingvisticheskij analiz [Generation of speech. Neuro-linguistic syntax analysis]. Moscow: publishing house of LKI. [in Russian].

Assmann, J. (2013). Communicative and Cultural Memory. Loci Memoriae Hungaricae - The Theoretical Foundations of Hungarian 'lieux de mémoire'Studies, 36-43. [in English].

Back, M. D., Stopfer, J.M., Vazire, S., Gaddis, S., Schmukle, S. C., Egloff1, B., Gosling, S. D. (2010). Facebook Profiles Reflect Actual Personality, Not Self-Idealization. Psychological Science, 3, 372-374. DOI: 10.1177/0956797609360756. [in English].

Bogomolova, E.I. (2014). Lichnostnaya identichnost $v$ usloviyakh virtualizaczii bytiya [Personal identity in the conditions of virtualization of being]. Chelovek. Soobshhestvo. Upravlenie - Person. Community. Management, 2, 108. [in Russian].

Borgmann, A. (2013). So who am I really? Personal identity in the age of the Internet. AI \& Soc, 28, 15-20. DOI: 10.1007/s00146-012-0388-0. [in English].

Davis, K. (2014). Youth Identities in a Digital Age: The Anchoring Role of Friends in Young People's Approaches to Online Identity Expression. In: Bennett A., Robards B. (eds) Mediated Youth Cultures. Palgrave Macmillan, London. DOI: 10.1057/9781137287. [in English].

Dirven, R., Polzenhagen, F., Wolf, H.-G. (2005). Cognitive Linguistics, Ideology, and Critical Discourse Analysis. Handbook of Cognitive Linguistics. Oxford: Oxford University Press. DOI: 10.1093/oxfordhb/9780199738632.013.0047. [in English].

Gladyshev, V.I. (2001). Kompensatornoe obshhenie: soczial no-filosofskij analiz [Compensatory Communication: A Socio-Philosophical Analysis]. Doctor dissertation, Ekaterinburg. [in Russian]. 
Gladyshev, V.I. (2012). Obshhenie v strukture samoutverzhdeniya lichnosti [Communication in the structure of self-affirmation of personality]. Vestnik Chelyabinskogo gosudarstvennogo universiteta - Bulletin of Chelyabinsk State University, 24, 64-67. [in Russian]. Goffman, I. (1958). The Presentation of Self in Everyday Life. University of Edinburgh Social Sicence Research Center, Edinburgh. [in English].

Jorgensen, M., \& Phillips, L. (2002). Discourse analysis as theory and method. London: Sage Publications. [in English].

Lysak, I.V., Kosenchuk, L.F. (2016). Formirovanie personalnoj identichnosti v usloviyakh setevoj kultury [The formation of personal identity in a network culture]. Moscow: publishing house «Sputnik +». [in Russian].

Machykova M. (2015). Media v konteksti psykholinhvistyky ta media psykholohii [Media in the context of psycholinguistics and media psychology]. East European Journal of Psycholinguistic, 2(2), 118-126. URL: http://esnuir.eenu.edu.ua/handle/123456789/9379. [in Ukrainian].

Mead, G.H. (2015). Mind Self \& Society. The Definitive Edition. Chicago and London: The University of Chicago Press. [in English].

Ogiyenko, I. S. (2012). Dyskurs ta pidxody do jogo analizu: poglyady na problemu suchasnyx anglomovnyx doslidnykiv [Discourse and approaches to its analysis: views on the problem of modern English-speaking researchers]. Naukovi zapysky Nacionalnogo universytetu «Ostrozka akademiya» - Scientific papers of the National University "Ostroh Academy», 23, 98-102. [in Ukrainian].

Patyrbaeva, K.V. (2012). Identichnost: soczialno-psikhologicheskie i soczialno-filosofskie aspekty: kollektivnaya monografiya [Identity: socio-psychological and socio-philosophical aspects: collective monograph / ed. By Patyrbaeva K.V.]. Perm: Perm State National Research University. [in Russian].

Romm, M.V., Luchikhina, L.F. (2011). Zarubezhnye tradiczii issledovaniya soczialnykh setej [Foreign traditions of the study of social networks]. Idei i idealy - Ideas and Ideals, 2, 86. [in Russian].

Schwabe, J. (2019): Role-taking theory and its application to interpersonal conflicts. Dissertation, LMU München: Faculty of Psychology and Educational Sciences. DOI: 10.5282/ edoc.24467. [in English].

Selyugina, P.B. (2012). Personal identity: the problem of adaptation or integrity? Advanced researches of psychological science, 261-268. [in English].

Terras, M. M., Ramsay, J., Boyle, E. A. (2015). Digital media production and identity: Insights from a psychological perspective. E-Learning and Digital Media, 12(2), 128-146. DOI: 10.1177/2042753014568179. [in English].

Tselmina, M.V. (2003). Psikhologicheskie usloviya razvitiya lichnosti [Psychological conditions for the personal identity development]. Candidate dissertation, Novosibirsk. [in Russian]. Varnelis, K. (2020). The meaning of network culture. Kultüros barai, 4. URL: https://www. eurozine.com/the-meaning-of-network-culturel [in English].

Vaughan, W. F. (1926). The psychology of compensation. Psychological Review, 33(6), 467-479. DOI 10.1037/h0070854. [in English]. 